\title{
Effect of low protein intake on acute exacerbations in mild to moderate chronic obstructive pulmonary disease: data from the 2007-2012 KNHANES
}

\author{
Sojung Park ${ }^{1 \#}$, Seo Woo Kim ${ }^{2 \#}$, Chin Kook Rhee ${ }^{3}$, Kyungjoo Kim ${ }^{3}$, Woo Jin Kim ${ }^{4}$, Kwang Ha Yoo ${ }^{5}$, Chang \\ Youl Lee ${ }^{6}$, Deog Kyeom Kim7, Yong Bum Park ${ }^{8}$, Ki-Suck Jung' ${ }^{9}$ Jin Hwa Lee
}

${ }^{1}$ Division of Pulmonary and Critical Care Medicine, Department of Internal Medicine, College of Medicine, Ewha Womans University, Seoul, Republic of Korea; ${ }^{2}$ Department of Internal Medicine, Dongbu Municipal Hospital, Seoul, Republic of Korea; ${ }^{3}$ Division of Pulmonary, Allergy and Critical Care medicine, Department of Internal Medicine, Seoul St Mary's Hospital, College of Medicine, The Catholic University of Korea, Seoul, Republic of Korea; ${ }^{4}$ Department of Internal Medicine and Environmental Health Center, School of Medicine, Kangwon National University, Chuncheon, Republic of Korea; ${ }^{5}$ Division of Pulmonary, Allergy and Critical Care Medicine, Department of Internal Medicine, Konkuk University School of Medicine, Seoul, Republic of Korea; ${ }^{6}$ Division of Pulmonary, Allergy and Critical Care Medicine, Department of Internal Medicine, Chuncheon Sacred Heart Hospital, Hallym University College of Medicine, Chuncheon, Republic of Korea; ${ }^{7}$ Division of Pulmonary and Critical Care Medicine, Department of Internal Medicine, Seoul Metropolitan Government-Seoul National University Boramae Medical Center, Seoul National University College of Medicine, Seoul, Republic of Korea; ${ }^{8}$ Division of Pulmonary, Allergy, and Critical Care Medicine, Department of Internal Medicine, Hallym University Kangdong Sacred Heart Hospital, Seoul, Republic of Korea; ${ }^{9}$ Division of Pulmonary, Allergy and Critical Care Medicine, Department of Internal Medicine, Hallym University Sacred Heart Hospital, Hallym University College of Medicine, Anyang, Republic of Korea

Contributions: (I) Conception and design: JH Lee; (II) Administrative support: JH Lee; (III) Provision of study materials or patients: CK Rhee, WJ Kim, KH Yoo, CY Lee, DK Kim, YB Park, KS Jung, JH Lee; (IV) Collection and assembly of data: All authors; (V) Data analysis and interpretation: S Park, SW Kim, K Kim; (VI) Manuscript writing: All authors; (VII) Final approval of manuscript: All authors.

\#These authors contributed equally to this work.

Correspondence to: Jin Hwa Lee, MD, PhD. Division of Pulmonary and Critical Care Medicine, Department of Internal Medicine, College of Medicine, Ewha Womans University, 25 Magokdong-ro 2-gil Gangseo-gu, Seoul 07804, Republic of Korea. Email: jinhwalee@ewha.ac.kr.

Background: Several researchers have reported that the amount of protein intake is associated with lung function and airflow obstruction. However, few studies have investigated the effect of low protein intake on acute exacerbations of chronic obstructive pulmonary disease. This study aimed to investigate the effect of low protein intake on exacerbations in mild to moderate chronic obstructive pulmonary disease.

Methods: We used data obtained from the Korean National Health and Nutrition Examination Survey (KNHANES) between 2007 and 2012, linked to the National Health Insurance claims data. The clinical outcomes and the rate of exacerbation were retrospectively compared between the low protein intake group and the non-low protein intake group which was stratified by quartile categories of protein intake in 2,069 patients with mild to moderate chronic obstructive pulmonary disease.

Results: The low protein intake group was significantly associated with older age, women, never smoker, low household income, and low education level, compared with the non-low protein intake group. The low protein intake group was significantly associated with increased hospitalization $(18.0 \%$ vs. $10.5 \%, \mathrm{P}<0.001)$ and emergency department utilization $(1.6 \pm 1.0$ vs. $1.1 \pm 0.4, \mathrm{P}=0.033)$ compared with the non-low protein intake group. In multivariate analysis, the low protein intake group was associated with hospitalization (odds ratio 1.46; 95\% CI, 1.09-1.96; $\mathrm{P}=0.012$ ). The multiple linear regression analysis revealed that the amount of protein intake was associated with $\mathrm{FVC} \%$ predicted $(\beta=0.048, \mathrm{P}<0.001)$ and $\mathrm{FEV}_{1} \%$ predicted $(\beta=0.022$, $\mathrm{P}=0.015)$.

Conclusions: Low protein intake was associated with an increased risk of exacerbations in mild to moderate chronic obstructive pulmonary disease. The data are available at the KNHANES website (https://knhanes. cdc.go.kr). 
Keywords: Chronic obstructive pulmonary disease (COPD); exacerbation; nutrient; protein; pulmonary function

Submitted Dec 03, 2020. Accepted for publication Aug 26, 2021.

doi: $10.21037 /$ jtd-20-3433

View this article at: https://dx.doi.org/10.21037/jtd-20-3433

\section{Introduction}

Chronic obstructive pulmonary disease (COPD) is characterized by progressive airflow limitations caused by chronic inflammation and remodeling of the airways (1). Systemic disease manifestations and acute exacerbations are associated with increased mortality risk in patients with COPD. Weight loss and muscle wasting are considered signs of terminal progression of the disease process and independent predictors of survival $(2,3)$. These changes are frequently accompanied by reduced exercise capacity and symptoms having a nutritional impact, such as anorexia and early satiety. In fact, $25 \%$ to $40 \%$ of patients with COPD are in a malnourished status, which is well known to be associated with decreased lung function and exercise intolerance as well as increased risk of acute exacerbations and hospitalization (2,4-7).

As nutritional support in stable COPD patients has been found to be effective in improving both nutritional intake and nutritional status, the role of nutritional assessment in patient management is increasing (6-9). Several animal studies have suggested that protein deficiency induces pulmonary emphysema and impaired lung growth $(10,11)$. In addition, there are reports that the amount of protein intake is associated with forced vital capacity (FVC), vital capacity and airflow obstruction in COPD $(12,13)$. However, few studies have investigated the effect of low protein intake on acute exacerbations of COPD.

In the present study, we investigated the effect of low protein intake on acute exacerbations in patients with mild to moderate COPD. We also investigated the relationship between low protein intake and lung function. We present the following article in accordance with the STROBE reporting checklist (available at https://dx.doi.org/10.21037/ jtd-20-3433).

\section{Methods}

\section{Study population}

The clinical outcomes and the rate of exacerbation were retrospectively compared between the low protein intake (LPI) group and the non-LPI group which was stratified by quartile categories of protein intake in patients with mild to moderate COPD. We used data obtained from the Korean National Health and Nutrition Examination Survey (KNHANES) between 2007 and 2012, linked to the National Health Insurance (NHI) claims data. The NHI system includes the medical reimbursement records for the entire Korean population. The KNHANES involves a cross-sectional, multistage probability-based sample representing the total non-institutionalized Korean civilian population. This information is available at the KNHANES website (https://knhanes.cdc.go.kr). The KNHANES contains de-identified data regarding demographics, underlying diseases, smoking history, spirometry results, laboratory data, and nutritional status. Trained nutritionists conducted interviews of each subject based on 24-hour dietary recall. Nutrient intakes were calculated using Korean food composition tables (14). Unfortunately, we were unable to investigate whether the source of protein was animal or vegetable.

We screened patients aged 40 years or older who underwent spirometry and the nutrition examination survey (Figure 1). Of these, the clinical outcomes of mild to moderate COPD were retrospectively analyzed by quartile categories of protein intake. Mild to moderate COPD was defined as the ratio of forced expiratory volume in one second $\left(\mathrm{FEV}_{1}\right)$ to $\mathrm{FVC}$ of less than 0.7 and $\mathrm{FEV}_{1}$ $\geq 50 \%$ of the predicted value. Spirometry was performed using equipment that met the American Thoracic Society performance criteria (15). After excluding two patients who consumed extreme amounts of protein which was defined as more than $300 \mathrm{~g} /$ day, a total of 2,069 patients were included in the present study.

The study was conducted in accordance with the Declaration of Helsinki (as revised in 2013). All KNHANES participants signed an informed consent form. In addition, it is open data which is available for everyone. All data were anonymously managed in all stages. Thus, ethical approval was not required, because the present study used data from 


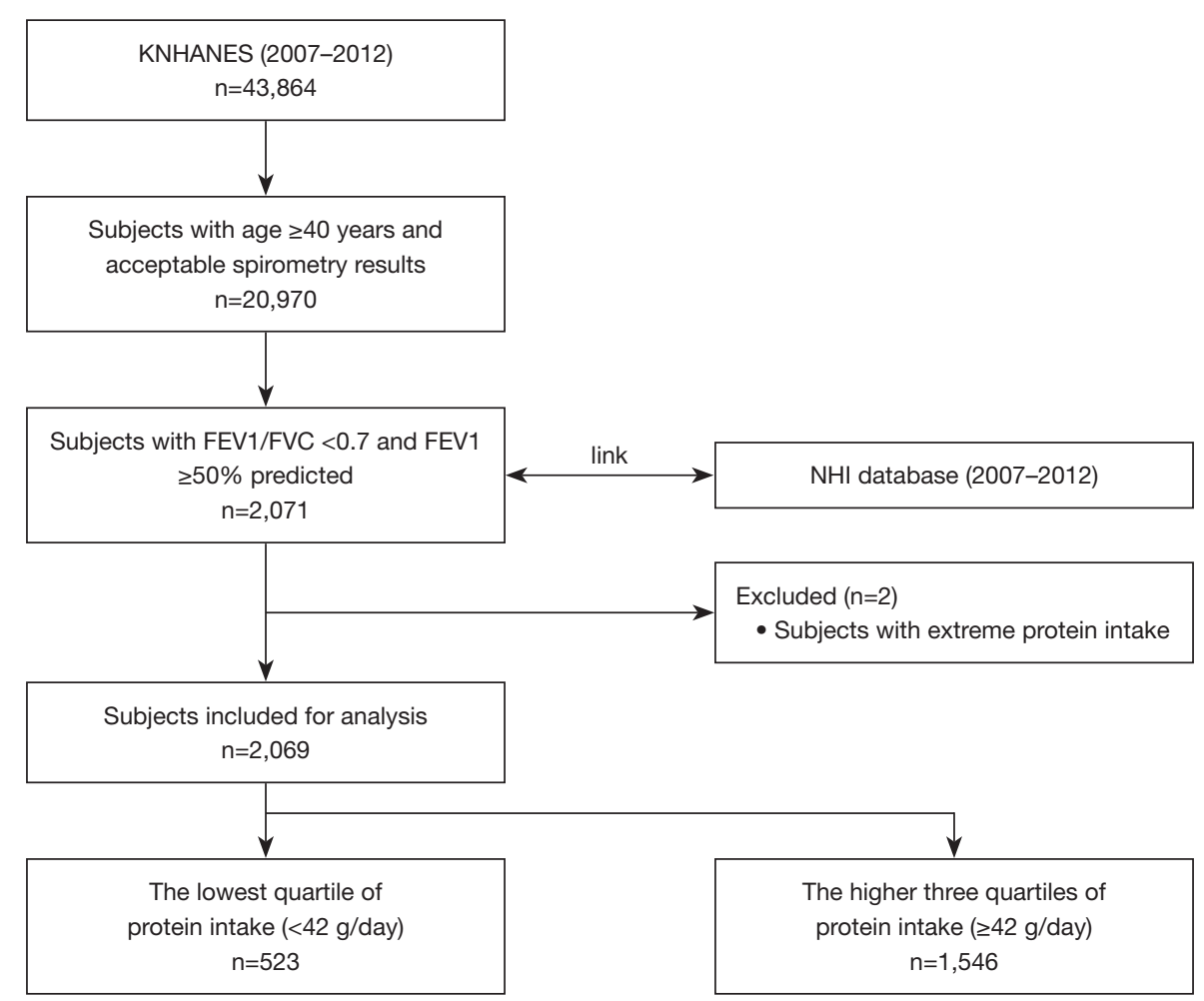

Figure 1 Flow chart of study identification, inclusion, and exclusion criteria. KNHANES, Korean National Health and Nutrition Examination Survey; $\mathrm{FEV}_{1}$, forced expiratory volume in 1 second; FVC, forced vital capacity; NHI, National Health Insurance.

those surveys retrospectively.

\section{Study design and data collection}

Patients with mild to moderate COPD were stratified by quartiles of dietary protein intake. The recommended daily protein intake for Korean over the age of 40 is $55-60 \mathrm{~g} / \mathrm{day}$ for men and $45-50 \mathrm{~g} /$ day for women (16). The distribution of protein intake is demonstrated in Figure 2. The lowest quartile of protein intake $(<42 \mathrm{~g} /$ day $)$ was classified as the low protein intake (LPI) group and the higher three quartiles ( $\geq 42 \mathrm{~g} /$ day) were classified as the non-LPI group. We collected demographic information, spirometry results, and laboratory data from the KNHANES database. To minimize potential over-diagnosis of airway obstruction, we also used the lower limit of normal (LLN) criterion which classifies the bottom $5 \%$ of the healthy population as abnormal, based on the normal distribution (17). The LLN of the $\mathrm{FEV}_{1} / \mathrm{FVC}$ was calculated using the following prediction equations: $125.77628-0.36304 \times$ age (years) $0.17146 \times$ height $(\mathrm{cm})$ for men and $97.36197-0.26015 \times$ age (years) $-0.01861 \times$ height $(\mathrm{cm})$ for women.
Based on the NHI claims data, the patient's hospitalizations, emergency department (ED) visits, intensive care unit (ICU) admissions, and prescription records were analyzed. An acute exacerbation of COPD was determined when patients were hospitalized or visited the ED with claim codes for the International Classification of Disease $10^{\text {th }}$ edition codes J42.X-J44.X and used inhaled short-acting bronchodilators and systemic corticosteroids.

\section{Statistical analysis}

All statistical analyses were performed using SAS ver. 9.2 (SAS Institute, Cary, NC, USA). Data are expressed as means \pm standard deviations or numbers (\%). Continuous variables were analyzed using either Student's $t$-test or Mann-Whitney tests and categorical variables were analyzed using Pearson's chi-square test. Multiple logistic regression analysis was performed by adjusting for confounding factors to assess the effect of LPI on exacerbations leading to hospitalization. The effect of protein intake on lung function was assessed using multiple linear regression analysis after adjusting for confounding factors. All tests for 


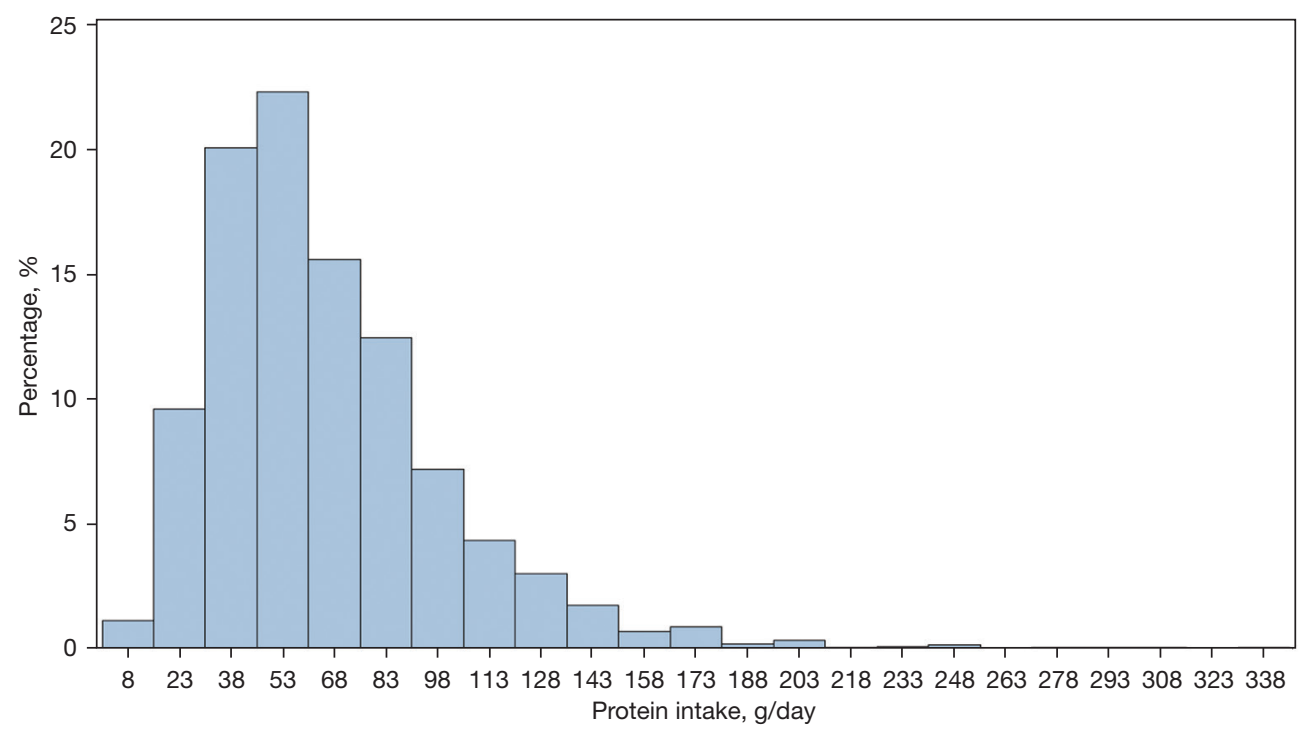

Figure 2 Distribution of protein intake in patients with mild to moderate chronic obstructive pulmonary disease.

significance were two-sided, and all variables with a $\mathrm{P}<0.05$ were considered to be significant.

\section{Results}

\section{Patient characteristics}

A total of 2,069 patients were included in the present study. The baseline characteristics of the patients are presented in Table 1. The mean age of the patients was $65.4 \pm 9.8$ years old; 1,468 (71.0\%) were men. There were several demographic differences between the two groups: the LPI group was associated with older age, women, low body mass index (BMI), never smoker, higher rate of Medical Aid, low household income, low levels of education, and not being married. In addition, the Charlson comorbidity index was significantly higher in the LPI group compared with the non-LPI group $(0.5 \pm 1.4$ vs. $0.2 \pm 0.9, \mathrm{P}<0.001)$. More patients in the LPI group had coronary artery disease and congestive heart failure.

\section{Nutrient intake status}

The LPI group was found to have not only low protein intake but also a low intake of other kinds of nutrients, such as carbohydrates, fat, and vitamins, compared with the non-LPI group (Table 2). Interestingly, significantly more patients in the non-LPI group reported that they had hyperlipidemia $(12.2 \%$ vs. $8.6 \%, \mathrm{P}=0.024)$; however, the total cholesterol level was actually significantly higher in the LPI group (193.7 $\pm 37.7 v s .188 .5 \pm 36.0 \mathrm{mg} / \mathrm{dL}, \mathrm{P}=0.006)$.

\section{Pulmonary function}

Spirometry results revealed that patients in the LPI group had a lower mean $\mathrm{FEV}_{1} / \mathrm{FVC}$ and a higher prevalence of airflow obstruction by the LLN criterion compared with those in the non-LPI group (Table 3). However, there were no significant differences in $\mathrm{FVC}$ and $\mathrm{FEV}_{1} \%$ predicted between the two groups.

\section{Exacerbations}

The LPI group was associated with increased hospitalization rates $(18.0 \%$ vs. $10.5 \%, \mathrm{P}<0.001)$ and frequent $\mathrm{ED}$ visits $(1.6 \pm 1.0$ vs. $1.1 \pm 0.4, \mathrm{P}=0.033$, Table 4$)$. In addition, they were significantly associated with frequent outpatient clinic visits (14.2 \pm 22.1 vs. $8.3 \pm 15.2, \mathrm{P}=0.011)$ and increased medical expenses $(2,831 \pm 4,891$ US dollars $v s$. 1,804 $\pm 3,281$ US dollars, $\mathrm{P}=0.015)$. However, there were no differences between the groups in the prevalence of ICU admission or lengths of hospital stay. To adjust for confounding factors that may affect exacerbations of COPD, we applied various models in multiple logistic regression analyses (Figure 3). The LPI group was independently associated with an increased risk of hospitalization in all models. In model 4 , which adjusted for $\mathrm{FEV}_{1} \%$ predicted, weight, smoking pack-years, and 
Table 1 Baseline characteristics of study population

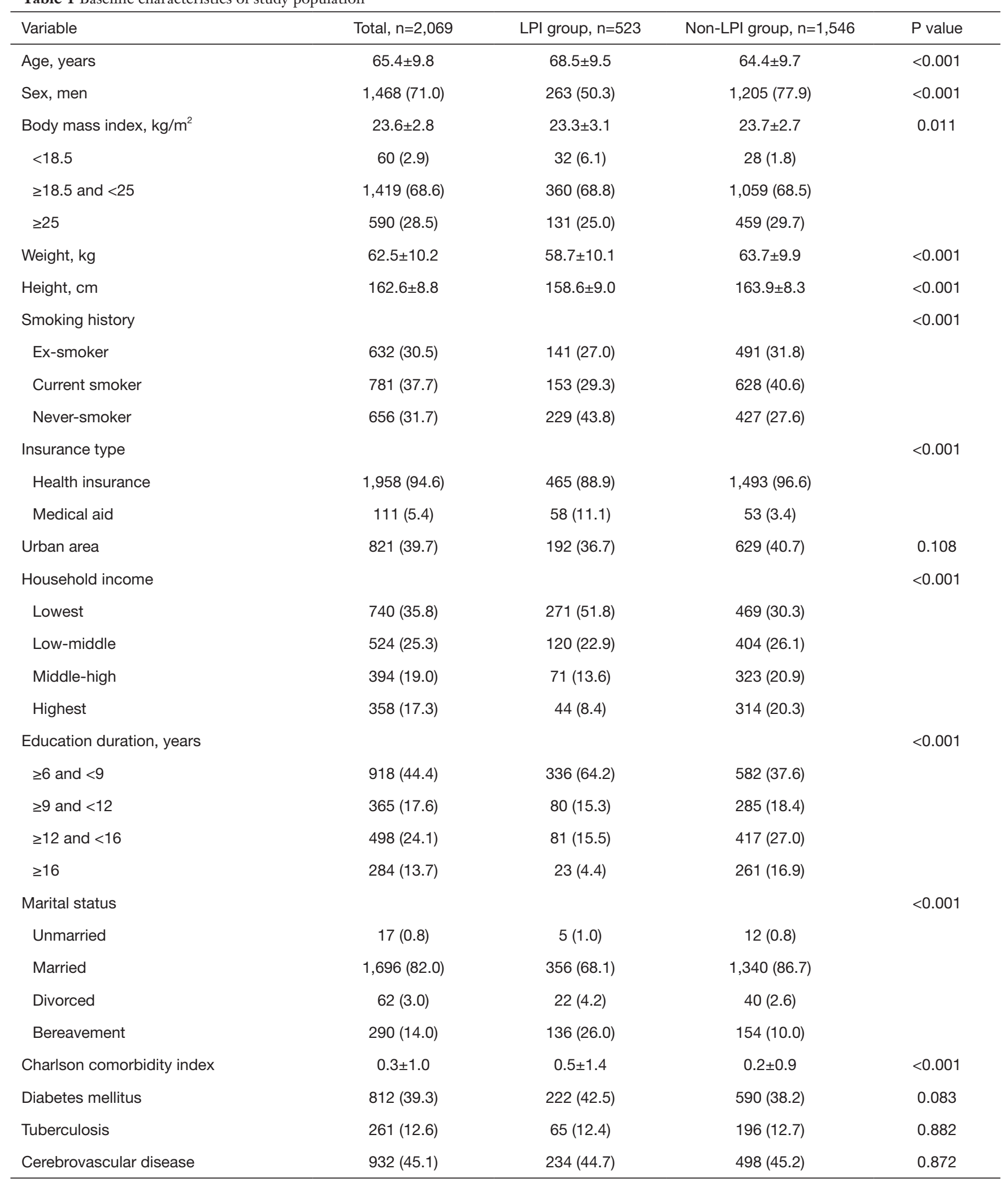

Table 1 (continued) 
Table 1 (continued)

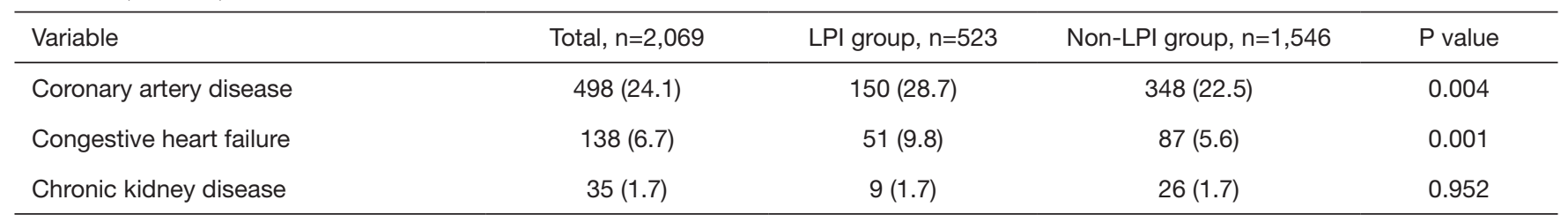

Data are presented as means \pm standard deviations or numbers (\%). LPI, low protein intake.

Table 2 Nutrient intake status and laboratory findings depending on the amount of protein intake in patients with mild to moderate chronic obstructive pulmonary disease

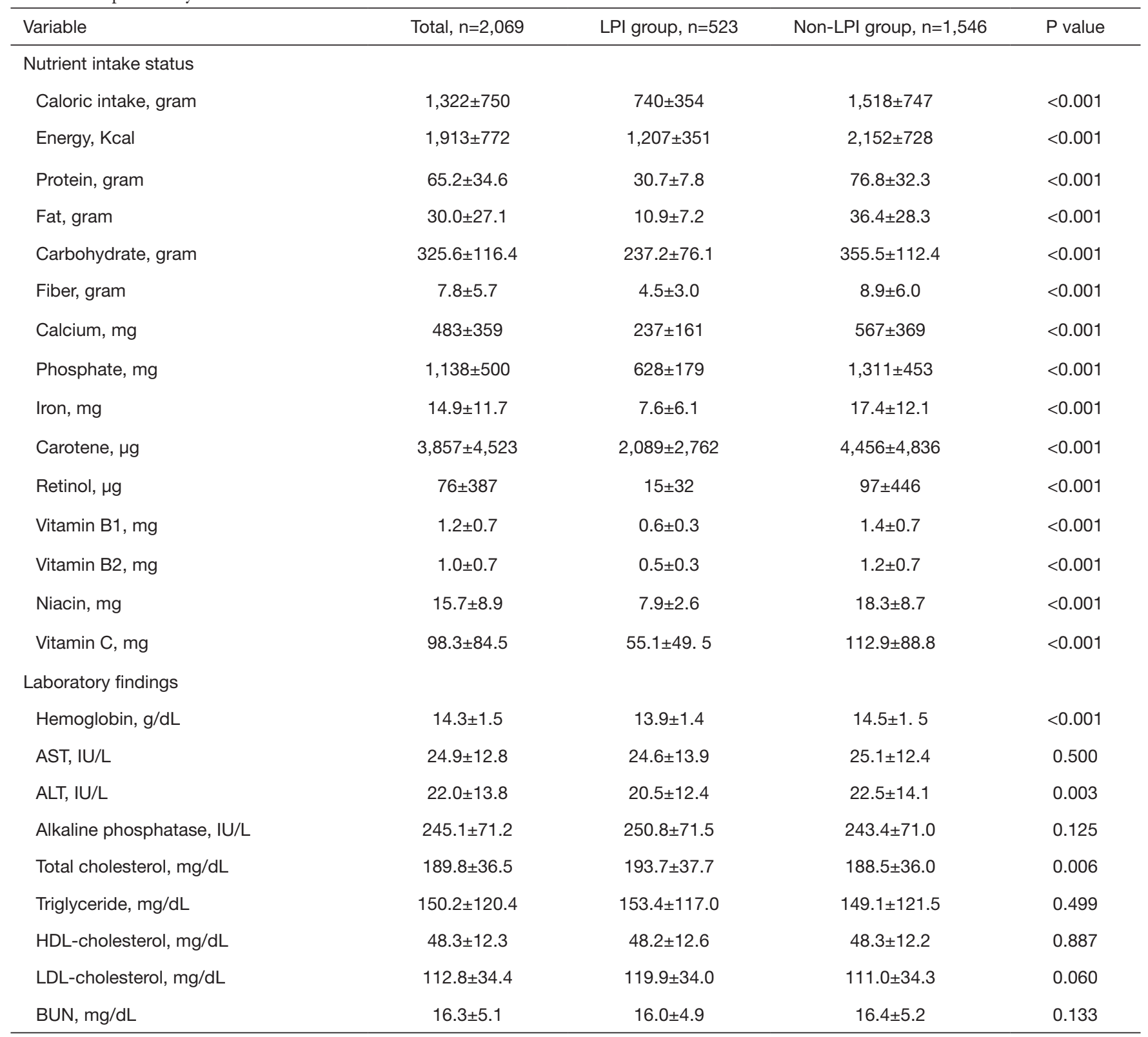

Table 2 (continued) 
Table 2 (continued)

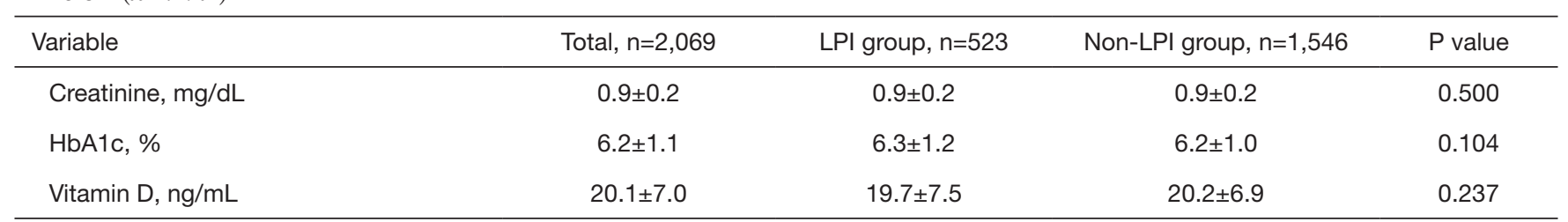

Data are presented as means \pm standard deviations. LPI, low protein intake; AST, aspartate aminotransferase; ALT, alanine aminotransferase; HDL, high-density lipoprotein; LDL, low-density lipoprotein; BUN, blood urea nitrogen.

Table 3 Spirometry results depending on the amount of protein intake in patients with mild to moderate chronic obstructive pulmonary disease

\begin{tabular}{|c|c|c|c|c|}
\hline Variable & Total, $n=2,069$ & LPI group, $n=523$ & Non-LPI group, $n=1,546$ & $P$ value \\
\hline $\mathrm{FEV}_{1} \%$ predicted & $78.8 \pm 13.7$ & $78.4 \pm 14.7$ & $78.9 \pm 13.3$ & 0.509 \\
\hline$\geq 80 \%$ & $943(45.6)$ & $231(44.2)$ & $712(46.1)$ & 0.454 \\
\hline$<80 \%$ and $\geq 50 \%$ & $1,126(54.4)$ & $292(55.8)$ & $834(53.9)$ & 0.454 \\
\hline $\mathrm{FEV}_{1} / \mathrm{FVC}<\mathrm{LLN}(\%)$ & $1,203(58.1)$ & $325(62.1)$ & $878(56.8)$ & 0.032 \\
\hline
\end{tabular}

Data are presented as means \pm standard deviations or numbers (\%). LLN prediction equations: $125.77628-0.36304 \times$ age $($ years) -

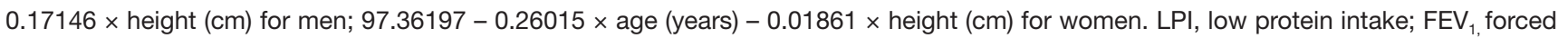
expiratory volume in 1 second; FVC, forced vital capacity; LLN, lower limit of normal.

household income, the LPI group had an increased risk of hospitalization [odds ratio (OR) 1.46; 95\%, confidence interval (CI), 1.09-1.96; $\mathrm{P}=0.012]$. Multivariate analysis revealed that low protein intake was a risk factor for frequent ED visits (OR 4.74; 95\% CI, 1.36-16.56; $\mathrm{P}=0.015)$, but not for ICU admission (OR 1.32; 95\% CI, 0.61-2.89, $\mathrm{P}=0.482$, Table S1). We also evaluated patients stratified by quartiles of protein intake by sex. The cut-off value of the lowest quartile of protein intake was $46 \mathrm{~g} /$ day in men and $32 \mathrm{~g} /$ day in women. As a result, the LPI group was independently associated with an increased risk of hospitalization in both sex subgroups (Table S2). We applied the same adjusted models for multiple linear regression analysis to investigate the relationship between protein intake and lung function (Table 5). In model 4 , the amount of daily protein intake was associated with $\mathrm{FEV}_{1} \%$ predicted $(\beta=0.022, \mathrm{P}=0.015)$, FVC $\%$ predicted $(\beta=0.048, \mathrm{P}<0.001)$ and $\mathrm{FEV}_{1} / \mathrm{FVC}(\beta=0.0001$, $\mathrm{P}=0.008)$.

\section{Discussion}

The present study demonstrated that low protein intake was associated with an increased risk of hospitalization and ED visits due to exacerbations in patients with mild to moderate COPD. To our knowledge, this is the first study to investigate the effect of low protein intake on exacerbations of COPD using large-scale data of Korean COPD patients.

Involuntary weight loss and muscle wasting in COPD are a consequence of the increased work of breathing, persistent inflammatory processes, and poor dietary intake resulting from anorexia and early satiety. Both metabolic and mechanical inefficiency contribute to the elevated energy expenditure during physical activity, while systemic inflammation increases resting energy expenditure (18-20). A previous study reported that protein synthesis and breakdown were elevated in weight stable COPD patients (21). This is consistent with another study that demonstrated that COPD patients showed decreased total body protein and lean body mass compared with healthy controls even when there were no differences in body weight and BMI (22). This elevated protein turnover is thought to be associated with low-grade inflammation. A negative nitrogen balance causes muscle wasting, which is known to be associated with reduced respiratory muscle strength and muscle mass.

In the present study, we found that the amount of protein intake was associated with $\mathrm{FEV}_{1}, \mathrm{FVC}$, and $\mathrm{FEV}_{1} / \mathrm{FVC}$. 
Table 4 Healthcare utilization and prescribed respiratory medicines depending on the amount of protein intake in patients with mild to moderate chronic obstructive pulmonary disease

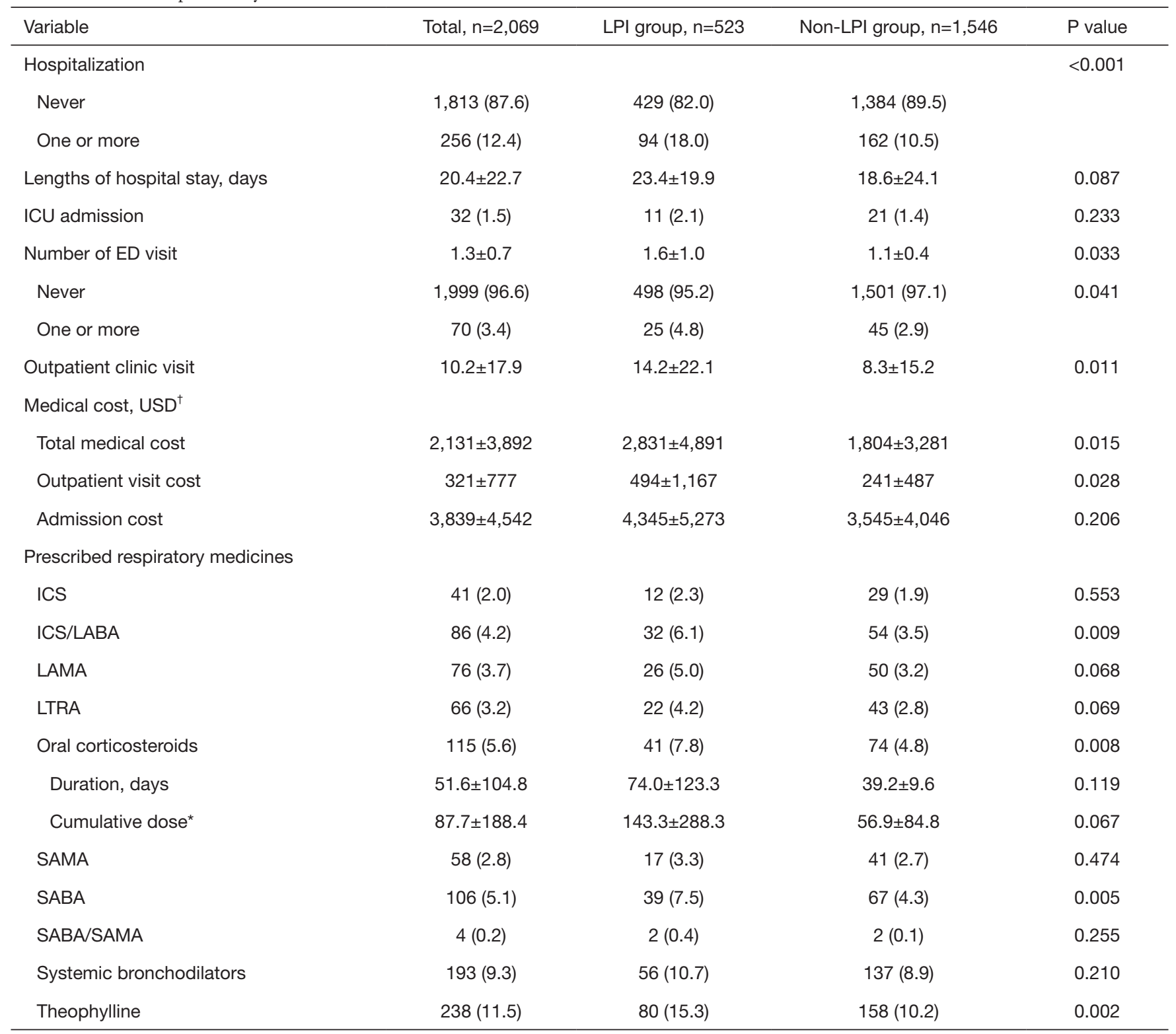

Data are presented as means \pm standard deviations or numbers (\%). ${ }^{\dagger}, 1$ USD $=1,000$ won; *, the equivalent dose of prednisone. LPI, low protein intake; ICU, intensive care unit; ED, emergency department; USD, United States dollar; ICS, inhaled corticosteroid; LABA, long-acting beta2-agnoist; LAMA, long-acting muscarinic antagonist; LTRA, leukotriene receptor antagonist; SAMA, short-acting muscarinic antagonist; SABA, short-acting beta2-agonist.

This is consistent with previous reports that demonstrated that protein intake was associated with lung function, such as FVC, vital capacity, and airway obstruction $(12,13)$. In the present study, patients in the LPI group consumed not only less protein but also fewer total calories, which might act as a confounding factor. However, Yazdanpanah et al. reported that there was no significant correlation between energy intake and lung function $(12,13)$. In addition, several animal experiments have shown that the lungs of proteindeficient rats appeared to be less compliant than those of normal rats, and rats fed a protein-deficient diet from the neonatal period showed abnormal lung development 
$(11,23,24)$. Although there are no reports about whether protein supplements improve lung function, it is well known that adequate nutritional supplementation, including protein, improves body weight, muscle mass, muscle length, and lung function $(9,25)$.

A previous prospective study demonstrated that patients with a lower BMI or those who had a weight reduction during the previous year had an increased likelihood of having an exacerbation compared with patients whose weight was either unchanged or increased (26). In addition, there are reports that hypoalbuminemia and hypoproteinemia are independent risk factors of exacerbation $(27,28)$. We could not find any data on the levels of protein, albumin, prealbumin, and retinol-binding protein, which have been considered as markers of visceral protein stores. However, multivariate analysis showed that low protein intake was an independent

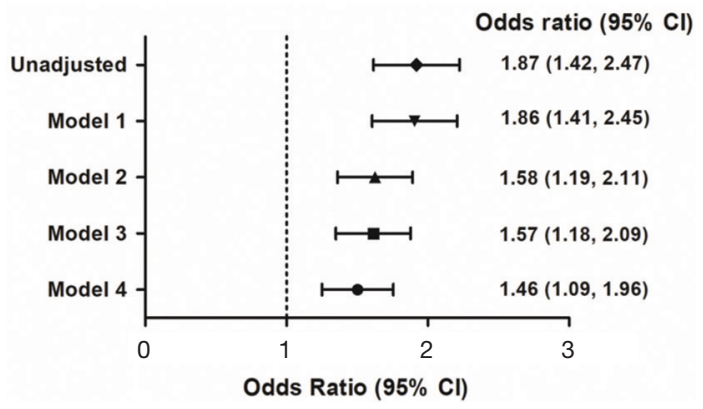

Figure 3 The odds ratio of exacerbation leading to hospitalization of the low protein intake group compared with the non-low protein intake group. Model 1: $\mathrm{FEV}_{1} \%$ predicted-adjusted. Model 2: $\mathrm{FEV}_{1} \%$ predicted and weight-adjusted. Model 3: $\mathrm{FEV}_{1} \%$ predicted, weight, and smoking pack-years-adjusted. Model 4: $\mathrm{FEV}_{1} \%$ predicted, weight, smoking pack-years, and household income-adjusted. risk factor of exacerbation of COPD after adjusting for factors that are well-known risk factors of exacerbation, such as $\mathrm{FEV}_{1} \%$ predicted and household income (29). Snider $e t a l$. demonstrated that nutritional supplementation was associated with reductions in readmission and length of hospital stay, possibly by reversing the disturbed energy balance in the acute phase of the illness (30). Therefore, a well-designed prospective study is needed to identify whether adequate protein supplementation has clinical benefits on the severity and frequency of exacerbations in COPD.

There are many differences in the baseline characteristics. Among these, older age, male sex, current smokers, less income, and comorbidities are known to be associated with increased risk of COPD exacerbation. Interestingly, the non-LPI group significantly included more men, and current smokers, as well as patients who were younger and earned more income. To adjust these confounding factors, we corrected these in the regression. On the other hands, these characteristics reflect the real world because data were obtained from the KNHANES which involves multistage probability-based sample representing the total noninstitutionalized Korean civilian population. Well-verified COPD exacerbation prediction tool needs to be applied to evaluate the quantitative risk affected by various factors other than amount of protein intake.

The present study has several limitations. First, the amount of protein intake was extrapolated from 24-hour dietary recall. This might not reflect long-term dietary pattern of the consumption of protein. If there were data available on the levels of markers of visceral protein stores, it would more correctly reflect any protein deficiency. However, the validity of 24-hour dietary recall has been well established, and the use of large scale data might compensate for any errors (31). Second, other risk factors

Table 5 Associations of protein intake and lung function in patients with mild to moderate chronic obstructive pulmonary disease

\begin{tabular}{|c|c|c|c|c|c|c|c|c|c|}
\hline Model & \multicolumn{3}{|c|}{$\mathrm{FEV}_{1} \%$ predicted } & \multicolumn{3}{|c|}{ FVC \% predicted } & \multicolumn{3}{|c|}{$\mathrm{FEV}_{1} / \mathrm{FVC}$} \\
\hline Unadjusted & 0.016 & 1.016 & 0.067 & 0.034 & 1.035 & $<0.001$ & 0.00011 & 1.0001 & 0.003 \\
\hline 1 & 0.021 & 1.022 & 0.017 & 0.048 & 1.049 & $<0.001$ & 0.00009 & 1.0001 & 0.021 \\
\hline 2 & 0.018 & 1.019 & 0.035 & 0.036 & 1.036 & $<0.001$ & 0.00014 & 1.0001 & $<0.001$ \\
\hline 4 & 0.022 & 1.022 & 0.015 & 0.048 & 1.048 & $<0.001$ & 0.0001 & 1.0001 & 0.008 \\
\hline
\end{tabular}

Model 1: weight; Model 2: smoking pack-years; Model 3: weight, smoking pack-years; Model 4: weight, smoking pack-years, household income. 
of exacerbation, such as the exacerbation history before the study period, comorbidities, infection, and compliance with medication, were not fully considered. In addition, low protein intake might be associated with low other nutrients intake or reduction in muscle mass which are risk factors for COPD exacerbation. These factors might affect the severity and frequency of exacerbations, and the appetite and protein intake amount. Especially, patients with both congestive heart failure and COPD might have more brittle clinical course because they have increased risk of developing severe ventricular failure, pulmonary congestion mimicking many signs and symptoms of COPD exacerbation, and have more limited pulmonary reserve.

In conclusion, low protein intake was associated with an increased risk of acute exacerbations leading to hospitalizations and ED visits in mild to moderate COPD patients. These findings suggest that encouraging patients to consume adequate protein or to use protein supplements may be important in their management. Further research is needed to clarify the implications of our results on COPD treatment.

\section{Acknowledgments}

Funding: This work was supported by the National Research Foundation of Korea (NRF-2020R1A5A2019210). The funding source had no role in design of the study, in data collection, analysis, or interpretation, and no role in writing the report or in the decision to submit the paper for publication.

\section{Footnote}

Reporting Checklist: The authors have completed the STROBE reporting checklist. Available at https://dx.doi. org/10.21037/jtd-20-3433

Data Sharing Statement: Available at https://dx.doi. org/10.21037/jtd-20-3433

Conflicts of Interest: All authors have completed the ICMJE uniform disclosure form (available at https://dx.doi. org/10.21037/jtd-20-3433). Chin Kook Rhee and Ki-Suck Jung serve as unpaid editorial board members of fournal of Thoracic Disease. All authors report funding from the Basic Science Research Program through the National Research Foundation of Korea (NRF) funded by the Ministry of Science, ICT \& Future Planning (2010-0027945). The funding source had no role in design of the study, in data collection, analysis, or interpretation, and no role in writing the report or in the decision to submit the paper for publication.

Ethical Statement: The authors are accountable for all aspects of the work in ensuring that questions related to the accuracy or integrity of any part of the work are appropriately investigated and resolved. The study was conducted in accordance with the Declaration of Helsinki (as revised in 2013). All KNHANES participants signed an informed consent form. In addition, it is open data which is available for everyone. All data were anonymously managed in all stages. Thus, ethical approval was not required, because the present study used data from those surveys retrospectively.

Open Access Statement: This is an Open Access article distributed in accordance with the Creative Commons Attribution-NonCommercial-NoDerivs 4.0 International License (CC BY-NC-ND 4.0), which permits the noncommercial replication and distribution of the article with the strict proviso that no changes or edits are made and the original work is properly cited (including links to both the formal publication through the relevant DOI and the license). See: https://creativecommons.org/licenses/by-nc-nd/4.0/.

\section{References}

1. Vogelmeier CF, Criner GJ, Martinez FJ, et al. Global Strategy for the Diagnosis, Management, and Prevention of Chronic Obstructive Lung Disease 2017 Report. GOLD Executive Summary. Am J Respir Crit Care Med 2017;195:557-82.

2. Wilson DO, Rogers RM, Wright EC, et al. Body weight in chronic obstructive pulmonary disease. The National Institutes of Health Intermittent Positive-Pressure Breathing Trial. Am Rev Respir Dis 1989;139:1435-8.

3. Schols AM, Slangen J, Volovics L, et al. Weight loss is a reversible factor in the prognosis of chronic obstructive pulmonary disease. Am J Respir Crit Care Med 1998;157:1791-7.

4. Schols AM, Soeters PB, Dingemans AM, et al. Prevalence and characteristics of nutritional depletion in patients with stable COPD eligible for pulmonary rehabilitation. Am Rev Respir Dis 1993;147:1151-6.

5. Vermeeren MA, Creutzberg EC, Schols AM, et al. Prevalence of nutritional depletion in a large out- 
patient population of patients with COPD. Respir Med 2006;100:1349-55.

6. Creutzberg EC, Wouters EF, Mostert R, et al. Efficacy of nutritional supplementation therapy in depleted patients with chronic obstructive pulmonary disease. Nutrition 2003;19:120-7.

7. Ahnfeldt-Mollerup P, Hey H, Johansen C, et al. The effect of protein supplementation on quality of life, physical function, and muscle strength in patients with chronic obstructive pulmonary disease. Eur J Phys Rehabil Med 2015;51:447-56.

8. Pingleton SK. Enteral nutrition in patients with respiratory disease. Eur Respir J 1996;9:364-70.

9. Collins PF, Stratton RJ, Elia M. Nutritional support in chronic obstructive pulmonary disease: a systematic review and meta-analysis. Am J Clin Nutr 2012;95:1385-95.

10. Kerr JS, Riley DJ, Lanza-Jacoby S, et al. Nutritional emphysema in the rat. Influence of protein depletion and impaired lung growth. Am Rev Respir Dis 1985;131:644-50.

11. Kalenga M, Henquin JC. Protein deprivation from the neonatal period impairs lung development in the rat. Pediatr Res 1987;22:45-9.

12. Yazdanpanah L, Shidfar F, Moosavi AJ, et al. Energy and protein intake and its relationship with pulmonary function in chronic obstructive pulmonary disease (COPD) patients. Acta Med Iran 2010;48:374-9.

13. Lee JH, Sim YS, Suh GY, et al. Diet and airway obstruction: a cross sectional study from the second Korean National Health and Nutrition Examination Survey. Korean J Intern Med 2010;25:132-9.

14. Food composition table - national rural living science institute - rural development administration, Suwon - 5th ed. International Network of Food Data Systems. Available online: http://www.fao.org/infoods/infoods/tables-anddatabases/korea/pt/ (1996)

15. Standardization of Spirometry, 1994 Update. American Thoracic Society. Am J Respir Crit Care Med 1995;152:1107-36.

16. The Korean Nutrition Society. Korean dietary reference intakes. Available online: http://www.kns.or.kr/English/ Publication.asp (2015)

17. Hwang YI, Kim CH, Kang HR, et al. Comparison of the prevalence of chronic obstructive pulmonary disease diagnosed by lower limit of normal and fixed ratio criteria. J Korean Med Sci 2009;24:621-6.

18. Kutsuzawa T, Shioya S, Kurita D, et al. Muscle energy metabolism and nutritional status in patients with chronic obstructive pulmonary disease. A $31 \mathrm{P}$ magnetic resonance study. Am J Respir Crit Care Med 1995;152:647-52.

19. Pouw EM, Schols AM, van der Vusse GJ, et al. Elevated inosine monophosphate levels in resting muscle of patients with stable chronic obstructive pulmonary disease. Am J Respir Crit Care Med 1998;157:453-7.

20. Satta A, Migliori GB, Spanevello A, et al. Fibre types in skeletal muscles of chronic obstructive pulmonary disease patients related to respiratory function and exercise tolerance. Eur Respir J 1997;10:2853-60.

21. Engelen MP, Deutz NE, Wouters EF, et al. Enhanced levels of whole-body protein turnover in patients with chronic obstructive pulmonary disease. Am J Respir Crit Care Med 2000;162:1488-92.

22. Piitulainen E, Areberg J, Lindén M, et al. Nutritional status and muscle strength in patients with emphysema and severe alpha(1)-antitrypsin deficiency. Chest 2002;122:1240-6.

23. Myers BA, Dubick MA, Gerreits J, et al. Protein deficiency: effects on lung mechanics and the accumulation of collagen and elastin in rat lung. J Nutr 1983;113:2308-15.

24. Matsui R, Thurlbeck WM, Fujita Y, et al. Connective tissue, mechanical, and morphometric changes in the lungs of weanling rats fed a low protein diet. Pediatr Pulmonol 1989;7:159-66.

25. Ferreira IM, Brooks D, White J, et al. Nutritional supplementation for stable chronic obstructive pulmonary disease. Cochrane Database Syst Rev 2012;12:CD000998.

26. Hallin R, Koivisto-Hursti UK, Lindberg E, et al. Nutritional status, dietary energy intake and the risk of exacerbations in patients with chronic obstructive pulmonary disease (COPD). Respir Med 2006;100:561-7.

27. Lin J, Xu Y, Wu X, et al. Risk factors associated with chronic obstructive pulmonary disease early readmission. Curr Med Res Opin 2014;30:315-20.

28. Yamaya M, Usami O, Nakayama S, et al. Malnutrition, Airflow Limitation and Severe Emphysema are Risks for Exacerbation of Chronic Obstructive Pulmonary Disease in Japanese Subjects: A Retrospective Single-Center Study. Int J Chron Obstruct Pulmon Dis 2020;15:857-68.

29. Kong CW, Wilkinson TMA. Predicting and preventing hospital readmission for exacerbations of COPD. ERJ Open Res 2020;6:00325-2019.

30. Snider JT, Jena AB, Linthicum MT, et al. Effect of hospital 
use of oral nutritional supplementation on length of stay, hospital cost, and 30-day readmissions among Medicare patients with COPD. Chest 2015;147:1477-84.

Cite this article as: Park S, Kim SW, Rhee CK, Kim K, Kim WJ, Yoo KH, Lee CY, Kim DK, Park YB, Jung KS, Lee JH. Effect of low protein intake on acute exacerbations in mild to moderate chronic obstructive pulmonary disease: data from the 2007-2012 KNHANES. J Thorac Dis 2021;13(10):5592-5603. doi: $10.21037 /$ jtd-20-3433
31. Kim YY, Kim MH, Choi MK. Validation of nutrient intake estimation based on one serving size. Korean J Food Nutr 2015;28:871-9. 


\section{Supplementary}

Table S1 The odds ratio of intensive care unit admission and emergency department visit of the low protein intake group compared with the non-low protein intake group in mild to moderate chronic obstructive pulmonary disease

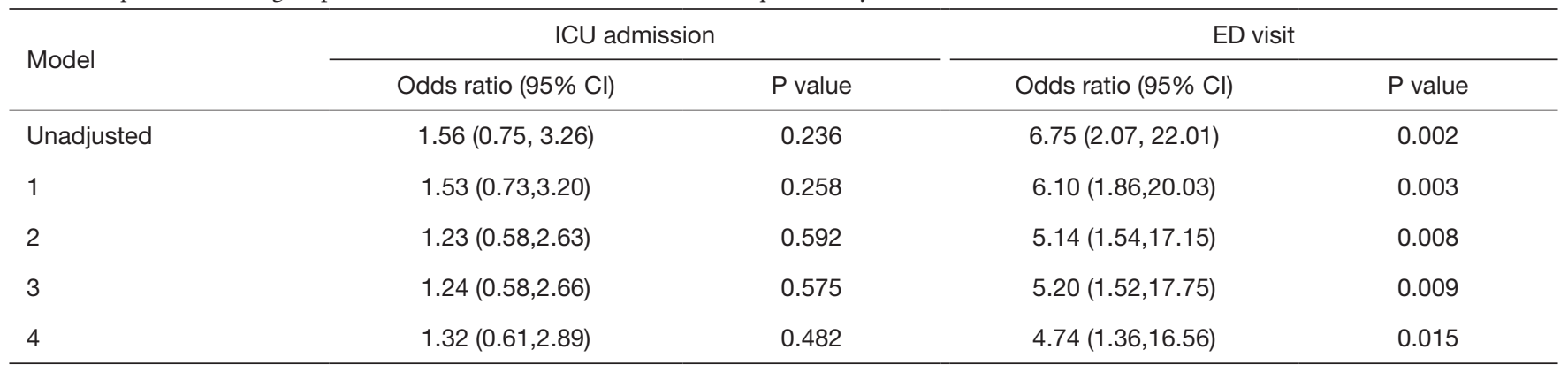

Model 1: $\mathrm{FEV}_{1} \%$ predicted; Model 2: $\mathrm{FEV}_{1} \%$ predicted, weight; Model 3: $\mathrm{FEV}_{1} \%$ predicted, weight, smoking pack-years; Model 4: $\mathrm{FEV}_{1} \%$ predicted, weight, smoking pack-years, household income. ICU, intensive care unit; ED, emergency department, CI, confidence interval.

Table S2 The odds ratio of exacerbation leading to hospitalization of the low protein intake group compared with the non-low protein intake group in both sex

\begin{tabular}{lcccc}
\hline & \multicolumn{2}{c}{ Men } & & Women \\
\cline { 2 - 3 } \cline { 4 - 5 } Unadjusted & Odds ratio $(95 \% \mathrm{Cl})$ & P value & Odds ratio $(95 \% \mathrm{Cl})$ & $\mathrm{P}$ value \\
Model 1 & $1.89(1.33-2.69)$ & $<.001$ & $1.83(1.16-2.87)$ & 0.009 \\
Model 2 & $1.86(1.31-2.65)$ & $<0.001$ & $1.87(1.19-2.95)$ & 0.007 \\
Model 3 & $1.62(1.13-2.32)$ & 0.009 & $1.85(1.18-2.93)$ & 0.008 \\
Model 4 & $1.62(1.13-2.33)$ & 0.009 & $1.71(1.07-2.76)$ & 0.027 \\
\hline
\end{tabular}

Low protein intake was defined as the lowest quartile of protein intake among all men and women, with $<46 \mathrm{~g} / \mathrm{day}$ for men and $<32 \mathrm{~g} / \mathrm{day}$ for women, respectively. Model 1: FEV 1 predicted; Model 2: FEV 1 \% predicted, weight; Model 3: FEV 1 \% predicted, weight, smoking pack-years; Model 4: $\mathrm{FEV}_{1} \%$ predicted, weight, smoking pack-years, household income. $\mathrm{Cl}$, confidence interval. 